\title{
In-Vitro Evaluation of Anti-Microbial and Anti-Oxidant Activity of Emblica Officinalis Juice Powder
}

\author{
Maryam Bincy Thomas ${ }^{1}$, Kashif Khan ${ }^{2}$, S. K. Sharma ${ }^{1}$, Lalit Singh ${ }^{1}$, M K Upadhyay ${ }^{2, *}$ \\ ${ }^{1}$ Sunder Deep Pharmacy College, Ghaziabad, UP, India \\ ${ }^{2}$ Biotech Park, Lucknow, UP, India \\ *Corresponding Author: drmkupadhyay@gmail.com
}

Copyright (C) 2013 Horizon Research Publishing All rights reserved.

\begin{abstract}
The present study was carried out to evaluate the in vitro antimicrobial and antioxidant activity of Emblica officinalis juice powder. The antimicrobial activity was assessed against gram positive and gram negative bacteria namely E.coli, Pseudomonas fluoresces, Bacillus subtilis, S.aureus, and fungi namely Aspergillus niger, Penicillium chrysogenum, Alternaria alternata, and Fusarium spp by agar well diffusion method. The antioxidant activity of the powder was determined in vitro using hydrogen peroxide scavenging activity method. The amount of total phenolic content was also determined by Folin Ciocalteau method. The result of the study revealed antibacterial and antioxidant activity. The Emblica officinalis powder showed no antifungal activity against the tested strains. The activity was found to be concentration dependent. The results of present study conclude that Emblica officinalis juice powder possess high antibacterial and antioxidant activity and can be further explored for the isolation of its bioactive compound.
\end{abstract}

Keywords Emblica Officinalis, Juice Powder, Antibacterial, Antioxidant

\section{Introduction}

Present day antibacterial therapy for bacterial diseases is mainly focused by the use of antibiotics and numerous synthetic antibacterial drugs. In spite of national and international policies for use of antibacterials, indiscriminate use of antibiotics is of great concern due to the development of resistant strains of organisms, toxicity, side effects and accumulation of drug residues in the body tissues and fluids (1). Therefore the use of plant extracts and phytochemicals with known antibacterial properties may be of immense importance in therapeutic treatments (2).

It is increasingly being realized that the majority of the diseases are mainly due to imbalance between pro-oxidant and anti-oxidant homeostatic phenomenon in the body. Pro-oxidant condition dominates either due to increased generation of free radicals or their poor quenching/ scavenging into the body. Free radicals are fundamental to any biochemical process and represent an essential part of aerobic life and metabolism. Equilibrium status of pro-oxidant/antioxidant reaction is disturbed during oxidative stress in living systems, which mediates damage to cell structures, including lipids, membranes, proteins and DNA. So there has been an upsurge of interest in the therapeutic potentials of medicinal plants as antioxidants in reducing such free radical induced tissue injury $(2,3)$.

Emblica officinalis (Amla) belongs to the family Euphorbiaceae. The fruit is acclaimed for its unique nutritional and rejuvenating properties. It is an important ingredient in chyavanaprash, and a constituent of triphala powder. It is useful vitiated conditions of tridosha, diabetes, inflammation, peptic ulcer, dyspepsia, cough, asthma, hepatopathy, leprosy, jaundice, diarrhea, dysentery, menorrhagia, grayness of hair, cardiac disorders $(2,3,4)$.

\section{Materials and Methods}

\subsection{Chemicals}

Mueller Hinton Broth (Himedia M391-100G), Mueller Hinton Agar No 2 (Himedia M1084-500G), Mueller Hinton Agar 2\% Glucose with methylene blue (Himedia M1825 -100G), Gentamicin (Product Code: TC026), Folin Ciocalteau reagent, Sodium carbonate, Gallic acid, Phosphate buffered saline, Hydrogen peroxide, Ascorbic acid etc.

\subsection{Test Organisms}

Microbial strains of gram positive and negative bacteria namely Escherichia coli, Staphylococcus aureus, Pseudomonas fluorescens, Bacillus subtilis and fungi namely Aspergillus niger, Penicillium chrysogenum, Alternaria alternata and Fusarium spp were collected from the Department of Microbiology, Biotech Park, Lucknow (table -4). 


\subsection{Preparation of Emblica Officinalis Juice Powder}

The fruits of Emblica officinalis were purchased from local market. Fruits were washed thoroughly to remove the debris and other adhering material. The fruits were chopped into small pieces and the seeds removed. The juice of the fruit was then extracted by using a cold pressure juice extractor and vacuum dried to obtain the powder. The powder obtained was then immediately packed in airtight container to prevent moisture attack.

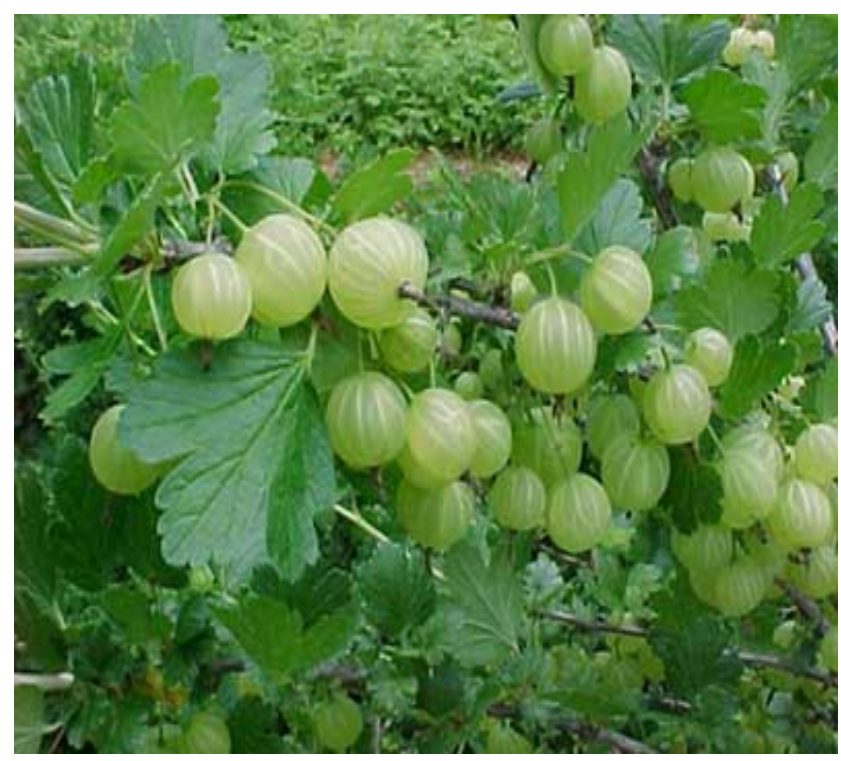

Figure 1. Fruits of Emblica officinalis

Table 1. List of Microbes and their MTCC Numbers used in the present study

\begin{tabular}{|c|c|c|}
\hline S.No & Microbes Name & MTCC No \\
\hline & E. coli & 1652 \\
\hline & Staphylococcus aureus & 96 \\
\hline & Pseudomonas fluorescens & 2421 \\
\hline & Bacillus subtilis & 2423 \\
\hline & Aspergillus niger & 2425 \\
\hline & Penicillium chrysogenum & 5108 \\
\hline & Alternaria alternata & 7202 \\
\hline & Fusarium & 156 \\
\hline
\end{tabular}

\subsection{Evaluation of Antimicrobial Activity}

\subsubsection{Antibacterial and Antifungal Assay}

The in vitro antibacterial and antifungal activity was tested against Emblica officinalis juice powder. Mueller Hinton Agar media was used for the culture of test organisms in case of bacteria and Mueller Hinton Agar along with 2\% glucose and methylene blue in the case of fungi. About 15 to $20 \mathrm{ml}$ of the respective media were poured into sterilized petri dishes and allowed to solidify. Wells of $9 \mathrm{~mm}$ in diameter were punctured in the media using sterile cork borer. Different concentrations of sample were seeded in the wells. Plates were incubated at $35^{\circ} \mathrm{C}$ for 24 hours in case of bacteria and $26^{\circ} \mathrm{C}$ for $48-72 \mathrm{hrs}$ in case of fungi. Antimicrobial activities were evaluated by measuring the inhibition zone diameters. Gentamicin was used as the standard antibacterial drug and Amphotericin as the standard antifungal drug $(2,5)$.

\subsubsection{Determination of Minimum Inhibitory Concentration (MIC)}

Emblica officinalis juice powder was screened for its minimum inhibitory concentration (MIC, $\mathrm{mg} / \mathrm{ml}$ ) against selected Gram positive organisms viz. S.aureus, Bacillus subtilis and Gram negative organism viz. E. Coli, Pseudomonas fluorescens by broth dilution methods as recommended by the National Committee for Clinical Laboratory Standards. Gentamicin was used as the standard antibacterial agent. Solutions of test compounds and reference drug were prepared at concentrations of 100, 50, $25,12.5,6.25,3.125 \mathrm{mg} / \mathrm{ml}$. The tests were carried out in triplicate against each of the test organism. The tubes were incubated at $35^{\circ} \mathrm{C}$ for 24 hours at $150 \mathrm{RPM}$. At the end of the incubation period, MIC values were recorded as the lowest concentration of the substance that gave no visible turbidity, i.e. no growth of the inoculated bacteria (6).

\subsubsection{Determination of Minimum Bactericidal Concentration (MBC)}

The concentration of the test compound that completely killed the organism was taken as MBC. Samples were taken in dilution tubes and inoculated on freshly prepared nutrient agar plates and incubated at $35^{\circ} \mathrm{C}$ for $24 \mathrm{hrs}$. The lowest concentration that showed no growth on plates was recorded as MBC.

\subsection{Evaluation of Antioxidant Activity}

\subsubsection{Total Phenolic Content}

The Total Phenolic content was determined by the Folin Ciocalteau method. The assay reaction contained the mixture of sample $(0.5 \mathrm{ml}$ of different dilutions) with $0.25 \mathrm{ml}$ of Folin Ciocalteau and $0.2 \mathrm{ml}$ of Sodium carbonate solution and the remaining volume made up to $10 \mathrm{ml}$ with distilled water. The calibration curve of polyphenols was prepared by using Gallic acid as a standard in the concentration of $10-50 \mu \mathrm{g} / \mathrm{ml}$ and mixed with the reagents above. After $2 \mathrm{hrs,} \mathrm{the}$ absorbance was measured at $765 \mathrm{~nm}$ to determine the total phenolic content. All determinations were carried out in triplicate. The total content of phenolic content in the extract was expressed in Gallic acid equivalents (GAE) which was calculated from the formula $(7,8,9)$ :

$\mathrm{T}=\mathrm{C} \times \mathrm{V} / \mathrm{M}$

Where, $\mathrm{T}=$ Total phenolic content in $\mathrm{mg} / \mathrm{g}$ plant extract, in $\mathrm{GAE}$

$\mathrm{C}=$ Concentration $(\mathrm{mg} / \mathrm{ml})$ of Gallic acid obtained from the calibration curve

$\mathrm{V}=$ Volume of extract $(\mathrm{ml})$ 
$\mathrm{M}=$ Weight $(\mathrm{g})$ of plant extract

\subsubsection{Hydrogen Peroxide Scavenging Activity}

Hydrogen peroxide scavenging activity was determined by the method described by Sharma et al. Solution of hydrogen peroxide $(20 \mathrm{mM})$ was prepared in phosphate buffer saline ( $\mathrm{pH}$ 7.4). Different concentrations of standard and sample $(1 \mathrm{ml})$ were added to $2 \mathrm{ml}$ of hydrogen peroxide solution in PBS. The observance of hydrogen peroxide at $230 \mathrm{NM}$ was determined after 10 minutes against a blank solution containing phosphate buffer without hydrogen peroxide. All the data presented are average of triplicate analysis. The percentage of hydrogen peroxide scavenging by the sample and the standard was calculated as follows $(9,10)$ :

$\%$ Scavenged $\mathrm{H}_{2} \mathrm{O}_{2}=\left[\left(\mathrm{A}_{0}-\mathrm{A}_{1}\right) / \mathrm{A}_{0}\right] \times 100$

Where, $\mathrm{A}_{0}=$ Absorbance of Control

$\mathrm{A}_{1}=$ Absorbance in the presence of sample and standard

\section{Results and Discussion}

\subsection{In-vitro Antibacterial Activity}

The Emblica officinalis powder was tested against four strains of bacteria namely E.coli, S.aureus, Pseudomonas fluorescens, and Bacillus subtilis. It showed maximum zone of inhibition against Bacillus subtilis and lowest against E.coli. The results of antibacterial activity measured in terms of the diameter of zone of inhibition in $\mathrm{mm}$ are shown in table 2 and Figure 2. The Amla juice powder exhibited ZOI values which are dose dependent. The ZOI values increased as the concentration increased. Gentamicin $(10 \mu \mathrm{g} / \mathrm{ml})$ was used as the standard antibacterial agent and it showed ZOI values against all the tested strains of bacteria. Hence it is indicated that Amla juice powder has great potential as antimicrobial compounds and can be used to treat infectious diseases caused by resistant microorganisms. The possible reason for antibacterial activity of Amla juice powder might be the presence of tannins in the fruits.

The minimum inhibitory concentration (MIC) and minimum bactericidal concentration (MBC) of Amla juice powder against the tested bacterial strains are recorded in table 3. Antimicrobial agents with low activity against an organism have a high MIC and MBC while highly active antimicrobial agents have a low MIC and MBC.

\subsection{In-vitro Antifungal Activity}

Emblica officinalis powder was tested for antifungal activity against four fungal strains viz. Aspergillus niger, Penicillium chrysogenum, Alternaria alternata, and Fusarium spp. The Emblica officinalis powder showed no antifungal activity against the tested strains.

Table 2. Sensitivity test of Bacterial species on Emblica officinalis juice powder

\begin{tabular}{|ccccc|}
\hline $\begin{array}{c}\text { Concentration } \\
(\mathrm{mg} / \mathrm{ml})\end{array}$ & E.coli & S.aureus & $\begin{array}{c}\text { Pseudomonas } \\
\text { fluorescens }\end{array}$ & $\begin{array}{c}\text { Bacillus } \\
\text { subtilis }\end{array}$ \\
0.5 & 6 & 7 & 6.5 & 7 \\
1.0 & 7.5 & 10 & 10.5 & 9 \\
1.5 & 8.5 & 11 & 12 & 11.5 \\
2.0 & 9.5 & 12 & 13.5 & 14 \\
$\begin{array}{c}\text { Gentamicin } \\
(10 \mu \mathrm{g} / \mathrm{ml})\end{array}$ & 15 & 20 & 20 & 29 \\
\hline
\end{tabular}

Table 3. Minimum Inhibitory Concentration (MIC) and Minimum Bactericidal Concentration (MBC) of Emblica officinalis juice powder

\begin{tabular}{|c|c|c|}
\hline Bacterial species & $\mathrm{MIC}(\mathrm{mg} / \mathrm{ml})$ & $\begin{array}{c}\mathrm{MBC} \\
(\mathrm{mg} / \mathrm{ml})\end{array}$ \\
\hline & & \\
E.coli & 6.25 & 25 \\
S.aureus & 6.25 & - \\
Pseudomonas fluorescens & 3.125 & 25 \\
Bacillus subtilis & 6.25 & 100 \\
& & \\
\hline
\end{tabular}

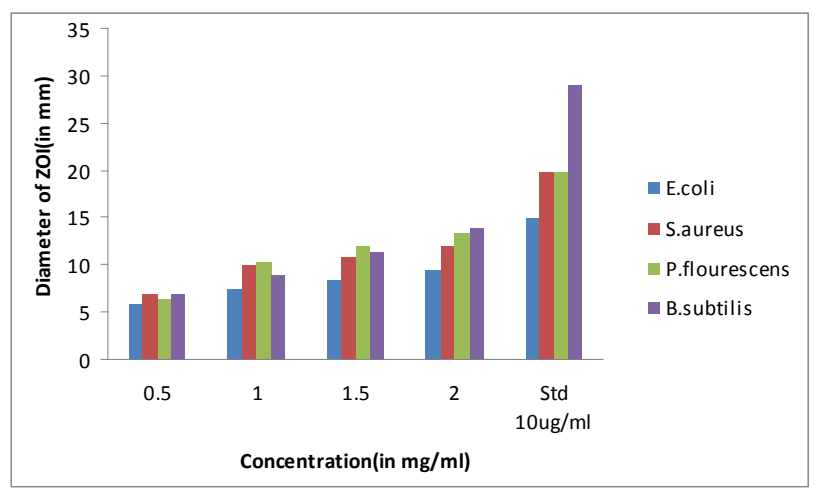

Figure 2. Graph shows Sensitivity test of Bacterial species on Emblica officinalis juice powder

\subsection{Antioxidant Activity}

\subsubsection{Total Phenolic Content}

The total phenolic content in the Emblica officinalis juice powder measured by Folin Ciocalteau reagent in terms of gallic acid equivalents (GAE) was found to be $390.8 \mathrm{mg} / \mathrm{g}$.

\subsubsection{Hydrogen Peroxide Scavenging Activity}

The Emblica officinalis juice powder was capable of scavenging hydrogen peroxide in a concentration dependent manner. The percentage reduction values for Emblica officinalis powder and Ascorbic acid are represented in table 4, Figure 3.

The results of present study reveal that Amla juice powder 
can scavenge free radicals or reactive oxygen species under in-vitro conditions. Scavenging of hydrogen peroxide by Amla powder may be attributed to the phenolic compounds. The presence of phenolic compounds and flavonoids acknowledge the antioxidant activity of the plant.

Table 4. Percentage reduction of $\mathrm{H} 2 \mathrm{O} 2$ by Emblica officinalis powder and Ascorbic acid

\begin{tabular}{|c|c|c|c|}
\hline S1 & $\begin{array}{c}\text { Concentration } \\
(\mu \mathrm{g} / \mathrm{ml})\end{array}$ & $\begin{array}{c}\text { \%eduction of } \\
\text { H2O2 by } \\
\text { Emblica } \\
\text { officinalis } \\
\text { powder }\end{array}$ & $\begin{array}{c}\text { \% Reduction of } \\
\text { H2O2 by } \\
\text { Ascorbic acid }\end{array}$ \\
\hline 1. & 100 & 17.55 & 38.14 \\
2. & 200 & 41.32 & 54.94 \\
3. & 300 & 56.06 & 66.74 \\
4. & 400 & 77.24 & 78.03 \\
5. & 500 & 92.58 & 95.22 \\
\hline
\end{tabular}

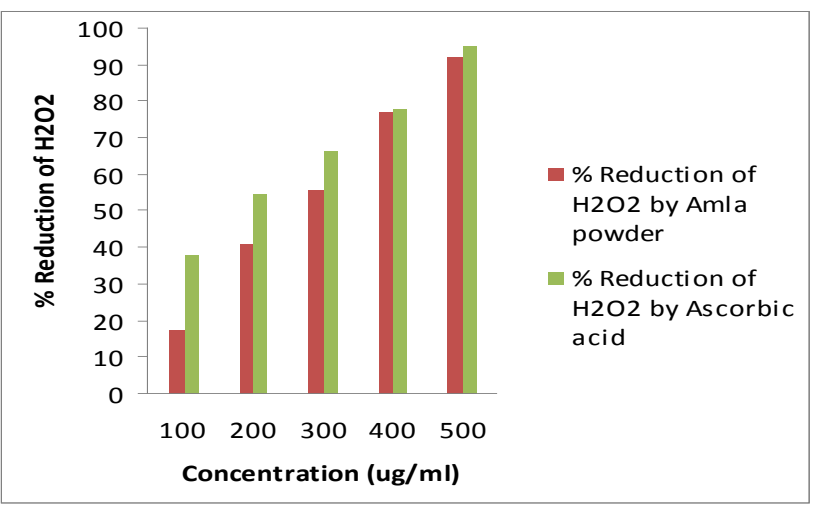

Figure 3. Percentage reduction of $\mathrm{H} 2 \mathrm{O} 2$ by Emblica officinalis powder and Ascorbic acid

\section{Conclusion}

The present study concludes that Emblica officinalis juice powder possesses high antibacterial and antioxidant properties and can be further explored in isolation of its bioactive compound. The presence of various phytoconstituents like flavonoids, tannins, saponins, phenolic compounds acknowledges the antimicrobial and antioxidant property of the plant.

\section{Acknowledgements}

The author is very grateful to Biotech Park, Lucknow for providing the facilities to conduct the study.

\section{REFERENCES}

[1] Satyajit G. Patil, Deshmukh A. A., Amol R. Padol, Dnyaneshwar B. Kale. In vitro antibacterial activity of Emblica officinalis fruit extract by tube dilution method. International Journal of Toxicology and Applied Pharmacology, Vol 2, No.4, 49-51, 2012.

[2] Gupta Priya, Nain Parminder, Sidana Jaspreet. Antimicrobial and Antioxidant Activity on Emblica officinalis seed extract. IJRAP, Vol 3, No.4, 591-596, 2012.

[3] Madhuri S, Pandey Govind, Verma Karuna S. Antioxidant, Immunomodulatory and Anticancer activities of Emblica officinalis: An Overview. International Research Journal of Pharmacy, Vol 2, No.8, 38-42, 2011.

[4] Anil Kumar, Anup Singh, Jyotsna Dora. Essential Perspectives for Emblica officinalis. International Journal of Pharmaceutical and Chemical Sciences, Vol 1, No.1, 11-18, 2012.

[5] Mir Monir Hossain, Kishor Mazumder, S. M. Moazzem Hossen, Tasmuna Tamrin Tanmy, Md. Jabir Rashid. In-vitro studies on Antibacterial and Antifungal activities of Emblica officinalis. International Journal of Pharmaceutical Sciences and Research, Vol 3, No.4, 1124-1127, 2012.

[6] Hans Raj Bhat, Satish Kumar Gupta, Udaya Pratap Singh. Discovery of potent, novel antibacterial hybrid conjugates from 4-aminoquinoline and 1,3,5-triazine: design, synthesis and antibacterial evaluation. RSC Advances 2012.

[7] Pornpimon Mayachiew, Sakamon Devahastin. Antimicrobial and Antioxidant Activities of Indian gooseberry and galangal extracts. LWT-Food Science and Technology, Vol 41, 1153-1159, 2008.

[8] Mohammad Ali Ebrahimzadeh, Seyed Mohammad Nabavi, Seyed Fazel Nabavi, Fatemeh Bahramian And Ahmad Reza Bekhradnia. Antioxidant And Free Radical Scavenging Activity Of H. officinalis L. Var. Angustifolius, V. odorata, B. hyrcana And C. speciosum. Pak J Pharm. Sci., Vol 23, No.1, 29-34, 2010.

[9] Serhat Keser, Sait Celik, Semra Turkoglu, Ökkes Yilmaz and Ismail Turkoglu. Hydrogen Peroxide Radical Scavenging and total Antioxidant activity of Hawthorn. Chemistry Journal, Vol 2, No.1, 9-12, 2012.

[10] Hemant Kumar Sharma, Atul Kumar. Evaluation of Total Phenol, Flavonoid and in vitro Antioxidant activity of Methanolic extract of leaves of Melastoma malabathricum Linn. Asian Journal of Chemistry, Vol 23, No.1, 434-438, 2011. 